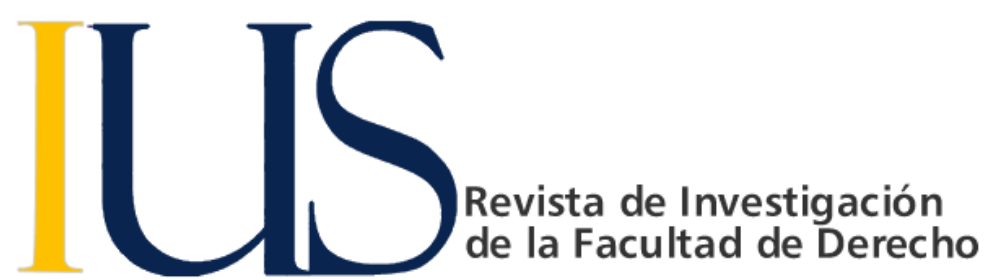

\title{
LA RESPONSABILIDAD FAMILIAR EMPRESARIAL EN LA GESTIÓN DE EMPRESAS. PARADIGMAS Y PERSPECTIVA JURÍDICA
} Erika Valdivieso López ${ }^{1}$

\begin{tabular}{ll}
\hline INFORMACIÓN DEL ARTÍCULO & RESUMEN \\
\hline $\begin{array}{l}\text { Historia del artículo: } \\
\text { Recibido el } 21 \text { de junio de } 2019\end{array}$ & El presente trabajo introduce la variable "familia" en el ámbito de la \\
Aceptado el 19 de setiembre de 2019 & Responsabilidad Social Corporativa, al considerar desde una perspectiva \\
& integral la relación entre la empresa, sus trabajadores y la sociedad. Para ello, \\
\hline Palabras clave: & reconoce la importancia de la familia en el desarrollo del tejido social; la \\
Responsabilidad Social Corporativa & necesidad de adoptar medidas de conciliación de la vida familiar y laboral - \\
Familia & desde un enfoque de corresponsabilidad - y la obligación ética y legal que la \\
Empresa & empresa tiene frente a sus trabajadores en el marco de la Responsabilidad \\
Conciliación vida laboral & Social Corporativa. Se parte de algunas experiencias e investigaciones \\
& realizadas sobre los beneficios de adoptar acciones de Responsabilidad \\
& Familiar en la empresa y se desarrolla el marco teórico que considera la \\
& inclusión de la "perspectiva de familia" en las políticas públicas y privadas; los \\
& entornos de desarrollo de los trabajadores y el ámbito de desarrollo de \\
& responsabilidad empresarial. Finalmente se realiza una revisión de la \\
& legislación actual que vincula el bienestar del trabajador y su familia, para \\
& determinar los mecanismos a través de los cuales los empresarios pueden \\
incorporar acciones de fortalecimiento de la familia a través de la gestión &
\end{tabular}

Family business responsibility in business management. Paradigms and legal perspective

\section{ABSTRACT}

\section{Keywords:}

Corporate Social Responsibility family

company

work life conciliation
The present work introduces the variable "family" in the field of Corporate Social Responsibility, considering from an integral perspective the relationship between the company, its workers and society. For this, he recognizes the importance of the family in the development of the social framework; the need to adopt measures to reconcile family and work life - from an approach of co-

\footnotetext{
${ }^{1}$ Abogada. Magíster en Derecho Privado Empresarial. Profesora del Área de Derecho de la Empresa de la Universidad Católica Santo Toribio de Mogrovejo. Chiclayo, Perú. Contacto evaldivieso@usat.edu.pe. ORCID: https://orcid.org/0000-0001-5363-6617
} 
responsibility - and the ethical and legal obligation that the company has against its workers within the framework of Corporate Social Responsibility. It is based on some experiences and research carried out on the benefits of adopting Family Responsibility actions in the company and the theoretical framework that considers the inclusion of the "family perspective" in public and private policies is developed; the development environments of workers and the scope of development of corporate responsibility. Finally, a review of the current legislation that links the welfare of the worker and his family is made to determine the mechanisms through which employers can incorporate family strengthening actions through business management

\begin{abstract}
"La principal responsabilidad social que cabe a la empresa contemporánea $y$, consiguientemente a su dirigencia, es la de cooperar entusiastamente a fortalecer la familia. El desafío presente y futuro para empresarios y altos directivos estriba, precisamente, en procurar que las organizaciones que gobiernan lleguen a ser empresas familiarmente responsables, signo de sentido práctico y de auténtica nobleza." Debeljuh
\end{abstract}

\section{Introducción}

El hombre es un ser social por naturaleza. Esta dimensión social se manifiesta en los distintos ámbitos de su vida, en el plano familiar, en el laboral y en la vida en comunidad. En cada espacio, la persona se desarrolla con los otros, lo que significa que la persona no solo crece como tal por aquello que puede recibir de cada ámbito, sino que también contribuye al desarrollo de los demás al tomar conciencia de su responsabilidad en la construcción del bien común.

Teniendo en cuenta los ámbitos de desarrollo de la persona y partiendo del hecho que ésta no se puede entender más que en su integralidad, podemos afirmar que la relación entre Familia, Empresa y Sociedad, es mucho más que una relación accidental. De la forma en que se entienda y asuma esta relación, dependerá precisamente el bienestar $-\mathrm{y}$ buen funcionamiento de ser el caso - de las instituciones señaladas.

Uno de los mecanismos que nos permite concretar positivamente y de manera integral y efectiva la relación Familia - Empresa y Sociedad es la Responsabilidad Social Corporativa (RSC), al presentarse como una "forma ética de gestión que implica la inclusión de las expectativas de todos los stakeholders (accionistas/inversionistas, colaboradores y sus familias, comunidad, clientes, proveedores, medio ambiente, gobierno y sociedad) alrededor de la empresa para lograr el desarrollo sostenible" (Marquina, 2011:14). Así, de la articulación de los intereses de la empresa con los intereses y expectativas de quienes la conforman se puede lograr el bienestar y desarrollo.

Ciertamente, la concepción de la empresa ha variado con paso de los años. De ser una organización de capital y trabajo exclusivamente dedicada a la obtención de beneficios en favor de sus dueños, ha pasado a considerarse una "auténtica organización de personas que trabajan coordinadamente para conseguir no solo ciertas metas o resultados económicos sino un bien común para todos" (Ordoñez, 2016:50). La trascendencia de los fines de la actividad empresarial viene siendo asumida por el empresario a través de las acciones de RSC.

En términos generales, la RSC abarca básicamente (i) La rendición de cuentas, (ii) el comportamiento ético, (iii) el respeto por los intereses de los stakeholders, (iv) el respeto al Estado de derecho y las normas internacionales de comportamiento y $(\mathrm{v})$ el respeto a los derechos humanos. Ahora bien, la mayoría de las acciones de RSC realizadas por las empresas actualmente, tienen que ver con la relación Empresa Sociedad ya que están destinados a reducir las externalidades negativas de las empresas, a morigerar el impacto de su actividad empresarial en el medio ambiente y en afianzar una imagen positiva de la empresa en la comunidad a través de mecanismos de proyección social. Sin embargo, es igualmente importante que las empresas dirijan sus acciones hacia sus trabajadores, quienes podrían considerarse el mayor valor de la empresa. Con ello, se completaría el esquema de relaciones antes citado y se promovería, de manera efectiva, el desarrollo integral del trabajador. La consideración de las necesidades del trabajador, pasa necesariamente por la atención a su dimensión familiar, sobre todo porque para cualquier persona, no existe nada más importante que su familia. De hecho, 
en la actualidad, la adopción de medidas destinadas a conciliar la vida familiar y laboral se ha convertido, para los trabajadores, en un factor importante a la hora de decidir asumir un cargo de dirección en alguna empresa.

Además de la importancia que el trabajador da a su familia, es evidente el valor que la familia (considerada en abstracto) tiene para la sociedad, pues ella contribuye al adecuado desarrollo del tejido social. Por esta razón, se hace necesario que la empresa incluya en sus acciones de RSC una nueva perspectiva: la perspectiva de familia.

Pliego (2014) define la Perspectiva de familia como:

El enfoque de las políticas públicas y privadas, como también de los programas de trabajo de las organizaciones de la sociedad civil, que considera que las estructuras y dinámicas de funcionamiento de las familias son fundamentales para el desarrollo y el bienestar de los individuos y de la sociedad (73).

Esta perspectiva, en el ámbito privado se puede incluir en lo que muchos han considerado llamar Responsabilidad Familiar Empresarial (RFE) O Responsabilidad Familiar Corporativa (RFC); entendida como uno de los aspectos de la RSC que implica la visibilización del trabajador y su familia, entendiendo esta realidad como parte de la empresa y frente a la cual, también mantiene un compromiso. Es decir, la RFE es la expresión más concreta del compromiso que tiene la empresa con sus primeros colaboradores.

Como se verá en este trabajo, la RFE tiene un referente concreto en las normas legales que buscan la conciliación de la vida familiar y laboral, o las normas que promueven la corresponsabilidad familiar, sin embargo, podemos notar que su contenido va más allá del aspecto normativo. Así, aunque existen normas legales que buscan la conciliación trabajo-familia, debemos resaltar que la RFE, supone también un deber ético que motiva la acción del empresario y que tiene al trabajador y a su familia como sujetos beneficiarios.

Por ello, consideramos importante incluir la variable "familia" en el ámbito de la Responsabilidad Social Corporativa, a partir de la inclusión de la perspectiva de familia, como política aplicable a la gestión de la empresa. Partiremos de algunas experiencias e investigaciones realizadas sobre los beneficios de adoptar acciones de Responsabilidad Familiar en la empresa y se desarrollará el marco teórico que considera la inclusión de la "perspectiva de familia" en las políticas públicas y privadas; los entornos de desarrollo de los trabajadores y el ámbito de desarrollo de responsabilidad empresarial. Se concluye con una revisión de la legislación actual que vincula el bienestar del trabajador y su familia, para determinar los mecanismos a través de los cuales los empresarios pueden incorporar acciones de fortalecimiento de la familia a través de la gestión empresarial.

\section{BREVES APUNTES SOBRE LA RESPONSABILIDAD SOCIAL CORPORATIVA}

\subsection{Noción de Responsabilidad Social Corporativa}

De la revisión de la literatura, se pueden extraer algunos elementos comunes a los que aluden los autores cuando definen la RSC. A decir de Marín y López (2016: 185-196) estos elementos son:

(i) La empresa tiene obligaciones que vas más allá de sus responsabilidades económicas, que son éticas, legales, sociales y medioambientales.

(ii) La RSC se debe situar en un nivel estratégico en la empresa, en la medida en que los principios que representa deben orientar la marcha de la empresa.

(iii) La empresa no solo debe atender las demandas de sus accionistas sino la de todos los grupos de interés con los que se relaciona.

(iv) La empresa será socialmente responsable si maximiza los impactos positivos y minimiza los negativos que genera en su entorno y en su relación con los grupos de interés.

Partiendo de lo señalado, la RSC puede definirse como una nueva forma de hacer negocios, en la que la empresa gestiona sus operaciones de forma sostenible en lo económico, social y ambiental, reconociendo los intereses de distintos públicos con los que se relaciona, como los accionistas, empleados, a comunidad, os proveedores, los clientes, considerando el medio ambiente y el desarrollo sostenible (Forum Empresa, 2009:4). Se presenta como una nueva conciencia empresarial en la que la empresa asume de manera efectiva, la responsabilidad sobre los efectos que su gestión empresarial genera en la sociedad y en sus stakeholders.

El primer concepto de RSC es el planteado por Bowen en 1953 que, partiendo de la relación deseable entre empresa y sociedad, alude a las "responsabilidades hacia la sociedad que se puede esperar que los empresarios asuman de forma razonable", afirmando que la responsabilidad social se refiere a "las obligaciones del empresario por conseguir las políticas, tomar decisiones o seguir líneas de actuación que sean deseables en los mismos términos y valores que lo desea nuestra sociedad" (Marín y López, 2016: 185196).

En esta primera definición podemos apreciar dos características, la primera es que se trata de una conducta razonable del empresario. Es decir, la acción 
es producto de un razonamiento previo del empresario, que al parecer identifica lo querido por la sociedad, con lo querido también por la empresa que dirige, lo que da lugar a la segunda característica del concepto: la identificación de la gestión empresarial por aquello que es deseado por la sociedad. En otras palabras, la gestión empresarial no se encontraría - tal como se desprende de esta primera definición - exclusivamente alineada a los intereses de los propietarios, sino más bien, alineada además, con los intereses de la sociedad (entendemos en este sentido, comunidad), pero en tanto sean razonables para el empresario.

La década siguiente recibe el aporte de Davis (Marín y López, 2016: 186), quien define la RSC como "las decisiones y las acciones tomadas por los empresarios que están, al menos en parte, más allá de su interés económico o técnico", aparejando a este concepto la consiguiente rentabilidad que se obtendría a través de la RSC. En la misma década, Frederick sostiene que la RSC "implica una postura pública hacia la sociedad y los recursos humanos y una disposición a ver cómo esos recursos deben ser usados para amplios fines sociales, y no simplemente para intereses circunscritos al ámbito de las empresas y las personas privadas" (Marín y López, 2016: 187), sin embargo, no deja de reconocer que, al encontrarse en una economía de mercado, el primer valor del empresario es la obtención de beneficios.

Una definición más actual y comúnmente aceptada por la doctrina es la que contiene el Libro Verde de la Comisión Europea (2001) en el que RSC se define como "la forma en que las empresas de forma voluntaria integran su concepción social y medioambiental en las prácticas operacionales y en su relación con los grupos de interés". A partir de aquí, podemos destacar dos elementos importantes de la RSC, primero, la voluntariedad; dado que las acciones de RSC dependen únicamente de la decisión del empresario, no podrían ser impuestas por el ordenamiento jurídico externo. A lo mucho, podría influir una especie de "presión social" o la necesidad de mejorar la imagen, pero, nada de ello es relevante si el empresario no valora como positiva la inclusión de dichas prácticas. Lo segundo es el protagonismo que vienen adquiriendo los grupos de interés o stakeholders como destinatarios - y en ocasiones, aliados - de las acciones de RSC que desarrolle la empresa. Dicha inclusión aún se encuentra en etapa de desarrollo, tal como lo demuestra la encuesta Perú Responsable (MTPE, 2015) en la que si bien el $78 \%$ de los empresarios considera que una organización socialmente responsable es aquella que "contribuye con el desarrollo sostenible, incluyendo la salud y bienestar de la sociedad", solo el 30\% la relaciona con que "toma en consideración las expectativas de las partes interesadas".

Aun cuando se va convirtiendo en una forma de gestión empresarial cada vez más aceptada, quedan espacios que definir e interiorizar por parte de los empresarios que van desde lo que se asume como su contenido, hasta el hecho que la asignación presupuestal no refleja la importancia que se le atribuye. Así, la encuesta antes citada señala que el $67 \%$ de los empresarios no incluye RSE en su organización "porque desconocen acerca de sus beneficios" o porque "carecen de un área responsable de RSE" (40\%), mientras que el 16\% señala que "es costoso gestionar la RSE".

\subsection{Sobre el contenido de la RSC}

Respecto al contenido, vale como referencia lo señalado por la norma ISO 26000 (2010:4), que identifica siete elementos básicos o fundamentales, a saber:

(i) Gobernanza con la organización, relacionados con los procesos para a toma de decisiones y estructura

(ii) Derechos humanos: comprende los derechos civiles y políticos, derechos sociales y culturales, entre otros.

(iii) Prácticas laborales: abarca la generación de condiciones adecuadas de trabajo y protección social, salud y seguridad en el trabajo, desarrollo humano, entre otros. Este aspecto es el que nos permitirá proponer la RFE.

(iv) Medioambiente: que contempla acciones como prevención de la contaminación, el uso sostenible de los recurso, protección del ecosistema, entre otros.

(v) Prácticas justas de operación: comportamientos éticos en relación con otros individuos o instituciones. Involucra aspectos como la anticorrupción, respeto de los derechos de propiedad y competencia justa.

(vi) Asuntos de consumidores: incluye las responsabilidades que tienen las organizaciones al ofrecer bienes y servicios a los consumidores. Estas se relacionan con el marketing, protección de datos, salud y seguridad del consumidor, etc.

(vii) Participación activa en el desarrollo de la comunidad: involucramiento con la sociedad a través de generación de empleo, inversión directa en la zona de incidencia, cooperación, etc.

Ya en el terreno práctico, podemos observar que las acciones de los empresarios en el Perú abarcan algunos de los aspectos señalados en la Norma ISO 26000, y se demuestra que buscan "respetar los derechos laborales y sindicales (52\%), contar con valores y normas de conducta dentro de su empresa (46\%), prevenir 
contaminación ambiental (39\%), dar oportunidades de formación a la gente de la comunidad (38\%), entregar información sobre el desempeño financiero y económico de la empresa al Estado (38\%), prevenir el trabajo infantil (27\%), combatir y/o evitar la corrupción (26\%), tener un diálogo abierto con la comunidad sobre cualquier tema polémico (26\%), dar información medioambiental clara y precisa sobre sus productos a sus clientes (23\%) (MTPE, 2015)

En el mismo sentido, en la encuesta de Global Research Marketing realizada el 2016 (Gestión, 2016) ante la pregunta sobre el tipo de actividades o programas de RSC desarrollados por las empresas, el 71\% realizaba donaciones, apoyo a entidades educativas y mejoramiento de las condiciones de vida de la comunidad. El $64 \%$ proyectos ambientales y el $51 \%$ proyectos relacionados con el reciclaje. No se menciona en esta encuesta, ninguna acción relacionada con los trabajadores $\mathrm{u}$ otros stakeholders (distintos a la comunidad).

Esta percepción positiva por parte del empresariado hace que las actividades relacionadas con la RSC se incrementen con el transcurso de los años, tal como lo señala la encuesta antes citada: el 2014 el 74\% de empresas, indicaron que tenían programas de RSC. Para el 2016, se incrementó a 98\%. Asimismo, el 99\% indicó que se trataba de un tema entre relevante y muy relevante. Sin embargo, pese a la importancia atribuida, solo el $28 \%$ invertía más del $1 \%$ de su presupuesto en programas de RSC y el $34 \%$ invertía menos del $1 \%$ de su presupuesto. (Gestión, 2016).

La relevancia de la RSE se evidencia también en su relación con el cumplimiento de los Objetivos de Desarrollo Sostenible. El 60\% de los entrevistados señaló que se relaciona con el objetivo de empleo digno y crecimiento económico, $58 \%$ con ciudades y comunidades sostenibles, $57 \%$ con buena salud y el $51 \%$ con la reducción de la desigualdad y erradicación de la pobreza (MTPE, 2016). Lo que se convierte en el impulso que necesita para incorporarse con mayor rapidez a la gestión empresarial.

Sin embargo, lo que debe advertirse es que la RSC no es solo la aplicación de acciones aisladas en determinada época del año (o solo con el fin de mejorar la imagen corporativa), sino que se trata de la incorporación a la gestión empresarial, de una determinada manera de ver la relación Empresa - Sociedad. Se trata de la aplicación transversal de principios éticos y de responsabilidad que abarcan todos los ámbitos de desarrollo de la empresa y que, así como beneficia, también involucra a todos los actores. La filantropía, es solo uno de los muchos elementos de la RSC, no el único. Igual de importante es el trabajo que se hace hacia dentro de la empresa, con los trabajadores y sus familias.

\subsection{RSC y Stakeholders}

Como se ha señalado anteriormente, las acciones de la RSC tienen estrecha relación con el medio ambiente (factores externos) y los grupos de interés que posibilitan, de manera directa o indirecta, el desarrollo de las actividades de la empresa. Esto en consideración a que estamos ante una comunidad de intereses (la telaraña alrededor de la empresa) donde conviven: (i) los inversionistas mayoritarios y minoritarios, (ii) los trabajadores, (iii) los consumidores y usuarios, (iv) los acreedores, (v) los tecnócratas, (vi) el Estado y (vii) hasta la propia comunidad (Echaiz, 2010:610). Cada uno de ellos tiene una expectativa particular respecto a la empresa, pero comulgan en que esas expectativas giran precisamente en torno a ellas.

Cuando en la década de los 80 se empieza a utilizar el concepto de grupos de interés o stakeholders, se definen como "aquellos individuos o grupos que pueden afectar o verse afectados por la consecución de los objetivos de la organización" (Marín y López, 2016:187) y se les atribuyen ciertas características específicas:

- Tienen derechos o intereses en la empresa y en sus actividades pasadas, presentes o futuras.

- Interactúan con la empresa para hacer posibles sus operaciones.

- Tienen interés en la buena marcha de la empresa ya que se ve afectados por la misma.

Sin embargo, en lo concerniente a los destinatarios de prácticas RSC, las comunidades (elementos externos) siguen siendo la prioridad para los empresarios. Así, en Perú se tiene que el 55\% de los proyectos de RSE se dirigen a éstas, mientras que los trabajadores reciben el $46 \%$ de atención, seguidos por la sociedad civil y el gobierno en un 31\% (MTPE, 2015).

Ahora bien, no debe olvidarse que incluso entre los grupos de interés encontraremos categorías, toda vez que la responsabilidad que tiene la empresa frente a sus accionistas no será la misma que tenga frente a sus acreedores, o incluso sus trabajadores. Por ello, se dice que para implementar la RSC de manera efectiva, es imperativo encontrar el punto de equilibrio entre "las expectativas de los distintos grupos de interés o stakeholders con lo que la compañía se relaciona: inversores, empleados, proveedores, clientes, comunidades; sin incurrir en desequilibrios o extracción fraudulenta del patrimonio social, y sin involucrar al legislador en la aprobación de normas imperativas" (Pérez, 2012: 39). La integridad del capital o la 
maximización de los beneficios de la empresa podrían ser los límites para el ejercicio de la RSE.

\section{FAMILIA Y POLÍTICAS PÚBLICAS}

\subsection{Importancia de la familia}

Nadie duda de la importancia de la familia para el bienestar de los individuos y de la sociedad. Así, la familia es la vía que más se valora para alcanzar la felicidad con 9.4 puntos -de un máximo de 10- (Libertad y Desarrollo, 2007). Es el espacio insustituible de desarrollo del ser humano y no existe ninguna institución pública o privada que brinde el mismo nivel de bienestar a sus miembros, que la familia. La razón de ello es, como señala Donati (2014) que la familia es el primero y más fundamental operador de la felicidad personal y social en cuanto que, por su propio modo de ser, estimula el desarrollo del capital humano (las cualidades individuales) y, en virtud de su peculiar estilo de vida, lo pone al servicio de los otros; poniéndolo al servicio de los otros, hace el bien a cada uno, esto es, vuelve feliz a toda persona que toma parte del hacer familia (33).

El carácter irremplazable de la familia también se justifica por las funciones estratégicas que cumple frente a la sociedad como (i) engendrar la próxima generación, (ii) criar y educar a la prole, (iii) desarrollar la cohesión intergeneracional de sus miembros, (iv) cimentar y consolidar la convivencia social, (v) transmitir pautas de conducta y valores, (vi) brindar seguridad a sus miembros y (vii) generar bienestar y desarrollo social (MIMP, 2016:19). Pero también, porque solo la familia garantiza la continuidad del Estado.

Se dice que la familia es la célula básica de la sociedad y el $86 \%$ de personas considera que la sociedad debería estar centrada en la familia, antes que en otras instituciones (UCSP, 2017: 14); y esta afirmación se asienta en el hecho que ninguna otra institución, asociación, empresa, universidad o colegio garantizan, como la familia, una continuidad generacional. Como señala Burgos (2004:166) la familia es el lugar de origen de la vida, el anclaje existencial por excelencia, el lugar de encuentro entre las generaciones y los sexos. A decir de Miró (2008) es aquella comunidad institucionalizada capaz de producir por sí misma, sin aportes de otras instituciones y personas, capital humano y capital social" (147).

Aun con lo dicho hasta aquí, no puede negarse que la familia, a lo largo de los años ha venido sufriendo transformaciones, tanto en su estructura (pérdida de relevancia de la estructura llamada "tradicional"), como en la posición que ocupa en la sociedad, hasta el punto de reducir su injerencia al ámbito meramente privado y, por ello, sin una efectiva atención a través de políticas públicas o privadas.

\subsection{El contexto de la familia}

Es preciso señalar que vivimos tiempos de cambios graves en la estructura social y económica en el Perú y Latinoamérica y de acuerdo a lo señalado por la OIT (2009), las transformaciones socio-demográficas producen variaciones en la organización interna de las familias, creando un nuevo balance de demanda y oferta de cuidados (14).

De acuerdo al documento Tipos y Ciclos de vida de los hogares (INEI, 2007); los cambios en las familias latinoamericanas se identifican en (i) el aumento de los hogares con jefatura femenina y la creciente participación de las mujeres en el mercado laboral (ii) la reducción del tamaño medio de la familia por el descenso del número de hijos y el mayor espaciamiento entre los partos (iii) la disminución de los hogares multigeneracionales y el aumento de los unipersonales (iv) Efecto de las migraciones por diversas causas (económicas, conflictos armados y otras), (v) aumento de la esperanza de vida de la población que incide en el aumento de las familias de hogares unipersonales, de adultos mayores y de hogares sin hijos, (vi) índices de fecundidad muy inferiores al nivel de reemplazo (vii) nuevas pautas de consumo y trabajo (viii) acceso masivo pero segmentado a los bienes y servicios sociales como educación, seguridad social y salud (16).

Estas circunstancias por las que atraviesa la familia - sin ninguna valoración - inciden directamente en el desarrollo de la persona en las diferentes etapas de su vida: demanda de servicios educativos, servicios de cuidado, oferta de vivienda, reemplazo generacional, cobertura de seguros, dificultad en el cumplimiento cabal de las funciones de la familia, etc. Afecta también a la persona en el ámbito del trabajo.

El ingreso masivo de la mujer como fuerza laboral, sin duda representa un hito en la forma como se concibe la relación Empresa-Trabajo-Familia. La OIT (2009) reconoce que la incorporación de las mujeres a la vida laboral ha tenido efectos importantes en la generación de riqueza de los países, el bienestar de los hogares y la disminución de la pobreza (14). Pero uno de los efectos más importantes ha sido la generación de una ruptura con la forma en la que tradicionalmente se asumían los roles y responsabilidades en la familia. Este cambio, sin embargo, no ha ido acompañado de políticas eficaces para la conciliación de la vida laboral y familia; lo que, a decir de Peña (2009) ha producido como efecto colateral la caída vertiginosa de la tasa de natalidad en el continente europeo, ante la incompatibilidad de la 
maternidad y empleo de calidad, [por lo que] muchas mujeres se quedan sin tener hijos" (3). Situación que no tendría por qué afrontar una mujer, es decir, no podemos forzarla a decidir entre desarrollarse laboralmente o tener hijos y formar una familia.

Se requiere entonces un cambio de paradigma - que evidentemente se encuentra en proceso - pero que requiere como respuesta, el involucramiento de todos los actores desde un enfoque de corresponsabilidad, sobre todo porque a una igual participación en la vida laboral de hombres y mujeres, tendría que corresponderle una equitativa distribución de las responsabilidades familiares. Aquí es donde aún existen brechas que superar.

En este aspecto, de acuerdo a la OIT (2009), el panorama en Perú y en América Latina, presenta las siguientes características (69):

- Los hombres tienen una menor participación e invierten menos tiempo en las actividades domésticas y de cuidado.

- El mayor tiempo dedicado a estas actividades por parte de las mujeres se incrementa notablemente en los tramos del ciclo vital asociados a la tenencia de niños.

- La jornada laboral de las mujeres es inferior a la de los hombres (y en consecuencia, también su remuneración), debido a la necesidad de atender responsabilidades domésticas y familiares.

- Incluso cuando las mujeres trabajan remuneradamente, la distribución de las tareas domésticas y de cuidado sigue siendo desigual.

La Encuesta Nacional de Hogares del INEI (2014) demuestra la diferencia en horas de dedicación entre hombres y mujeres para distintas actividades. Se puede notar que la mayor diferencia se encuentra en actividades que suponen el cuidado de algún miembro del hogar, cuidado de niños pequeños y actividades culinarias.

\section{Ver TABLA N01 (al final)}

El problema se presenta precisamente en este último aspecto, en la atención de las actividades propias del hogar y es la parte que requiere un cambio de paradigma respecto a cómo se asumen las responsabilidades en el hogar, más aún si la sobrecarga de trabajo doméstico y de cuidado en las mujeres, genera también consecuencias negativas para las familias. Estas experimentan mayores dificultades para proporcionar una atención adecuada a niños y niñas, adultos mayores, enfermos. Se priva a los hombres de participar activamente de la crianza de sus hijos y del cuidado de sus familiares, minando sus lazos afectivos y su desarrollo integral; niños y niñas no cuentan con roles masculinos presentes en su vida cotidiana dificultando su desarrollo integral (OIT, 2009:6).

La existencia de estas brechas se debe a factores muy variados, unos tienen que ver con la permanencia de roles tradicionalmente asumidos, con la naturaleza masculina o femenina, con la educación, e incluso con el sentido de la oportunidad. Sin embargo, en lo que podríamos concentrarnos hoy es en cómo contribuir a la reducción de estas desigualdades a partir de la implementación de acciones concretas desde la empresa.

Consideramos que se puede contribuir a esto si por un lado se asume adecuadamente el significado de la corresponsabilidad familiar y si el trabajador - o colaborador - encuentra en su empresa el apoyo necesario para ejercerla, ya que ahora mismo, según OIT (2009) "el esfuerzo que realizan las personas para conciliar vida familiar y laboral genera una enorme tensión que afecta su rendimiento y conlleva una menor productividad" (106).

Por esta razón, consideramos importante incluir la corresponsabilidad como mecanismo que contribuya a la conciliación de la vida laboral y familiar, con el fin de conseguir una igualdad efectiva de oportunidades en el trabajo para varones y mujeres y para lograr una distribución más justa de sus responsabilidades familiares. En otras palabras, buscar hacer compatible el trabajo con la protección de la familia. Ello solo se logra si las medidas que busquen armonizar la vida familiar y laboral tienen como destinatarios a todos: padres y madres, de esta manera se contribuye a promover el cambio de roles y estereotipos en términos de corresponsabilidad; lo contrario implicaría insistir en la discriminación de las mujeres y de los hombres que han asumido sus responsabilidades familiares.

\subsection{Políticas familiares y el Enfoque de Familia}

La importancia social de la familia genera la obligación de su protección por parte del Estado, así se encuentra reflejada en el Art. $4^{\circ}$ de la Constitución Política Peruana (CPP) cuando señala que "La comunidad y el Estado protegen especialmente al niño, al adolescente, a la madre y al anciano en situación de abandono. También protegen a la familia y promueven el matrimonio. Reconocen a estos últimos como institutos naturales y fundamentales de la sociedad". Asimismo, desde el plano de su relación con la sociedad, el Estado señala que:

"La[s] familia[s] como institución natural se entiende[n] en un sentido dinámico: como un grupo social organizado constituido por personas relacionadas por vínculos de consanguinidad, afinidad y/o afecto, donde 
se da un conjunto de relaciones e interacciones entre sus integrantes en el ámbito de lo doméstico, organizando la vida cotidiana y la reproducción económica, social y generacional; y como una institución social, en tanto constituye una red de interrelaciones donde se forman las identidades sociales que interactúa con el universo de lo social en todas sus dimensiones: social, económica, política, ofertando ciudadanos que ejercen esos roles (trabajadores/as, consumidores/as, ciudadanos/as, etc.),y que por lo tanto, también está afectada por factores exógenos a ella"(MIMP, 2014:19).

Sin embargo, se debe entender que el Estado no es el único que debe asumir esta obligación. La sociedad también debe ser solidaria con la familia. Es decir, tendría que haber mayor sensibilidad social para entender que la familia es un hecho que requiere protección, cuidado y fomento. La revalorización de la familia es imperativa en una sociedad - como la contemporánea - en la que se concede singular importancia al éxito individual y profesional, pero deja de valorar positivamente-especialmente en los medios de comunicación y en el sistema educativo - otras formas de realización personal vinculadas a los demás y al bien común, como la vida familiar (PIAF, 2017).

Considerar que la familia, y tanto más, sus estructuras y dinámicas de funcionamiento, son fundamentales para el desarrollo y el bienestar de los individuos y de la sociedad, es lo que caracteriza una perspectiva de familia que, como enfoque puede aplicarse a las políticas públicas y privadas.

En efecto, la perspectiva de familia también puede incorporarse en el ámbito privado, "en los programas de trabajo de las empresas y de las organizaciones de la sociedad civil" (Pliego, 2014:74). Las empresas privadas que asumen esta perspectiva en su organización, no solo reconocen la importancia de la familia, sino que entienden a cada uno de sus empleados como miembros de una, como parte de una estructura que lo trasciende e influye en su bienestar personal y en consecuencia, en su rendimiento laboral. En este sentido, la protección y promoción de la familia y la conciliación de la vida familiar y laboral, debería ser implementado como política de las empresas privadas, más allá de lo que pueda señalar o exigir el propio Estado.

\section{EMPRESA Y FAMILIA}

\subsection{Responsabilidad Social Corporativa con enfoque de familia}

Como se dijo anteriormente el compromiso de las empresas con la sociedad se ha centrado principalmente en la responsabilidad social externa (el cuidado del cliente y del proveedor, la ecología ambiental, la lucha contra el trabajo infantil, etc.). Por ello, la actuación responsable de una empresa en el ámbito interno (su relación con directivos y empleados) ha recibido menor atención que la dirigida a los stakeholders externos. (Ordoñez, 2017: 55). Este hecho tiene sentido en un entorno en el que no se ha interiorizado adecuadamente la RSC o se considera que sus "ventajas" son únicamente de imagen o posicionamiento en el mercado, de cara al público consumidor.

Ahora bien, todos los empresarios coinciden en que el principal activo de la empresa son sus trabajadores. Siendo esto así, una visión humanista de la relación Empresa-Trabajador supone asumir su realidad familiar $y$, en consecuencia, reconocer que la familia se convierte, sino en otro stakeholder de la empresa, por lo menos en un elemento fundamental cuando se trata del trabajador.

Incorporar a las acciones de RSC el Enfoque de Familia, da como resultado que la empresa empiece a plantearse la incorporación sistemática de acciones y políticas empresariales que contribuyan al bienestar del trabajador a través de su familia; esto es, buscar una verdadera conciliación de la vida familiar del trabajador, con su entorno laboral. Este es el punto medular de la Responsabilidad Familiar Empresarial.

Se hace necesario entonces que el trabajador y su familia sean considerados uno de los grupos de interés que efectivamente involucren a la empresa en términos de RSE.

En la encuesta de Perú Responsable (MTPE, 2015) se estableció que solo el $25 \%$ de empresarios contaban con una política RSE que involucrara a los grupos de interés, pese a considerarla importante. Asimismo, solo el $22 \%$ vinculó los proyectos de RSE con acciones destinadas a beneficiar a los grupos de interés. Pese a esto, para quienes incluyen en los proyectos de RSE a los grupos de interés, los trabajadores destacan entre las preferencias para aplicación de este tipo de proyectos con un $46 \%$. Antes que ellos están las comunidades con 55\%, lo que afirma la idea de proyectar la RSE hacia afuera, antes que hacia adentro.

\subsection{La RFE y los entornos empresariales}

El aspecto central de la RFE es asumir la relación Empresa- trabajo-familia. La forma como se asuma esta relación dará lugar a distintos entornos en los que el trabajador se desarrolle. En un reciente estudio se evaluó el grado de involucramiento de la empresa con el bienestar de sus trabajadores a partir de la aplicación de medidas de conciliación de la vida laboral y familiar 
(Estudio IFREI 5.1 sobre la conciliación de la vida laboral y familiar, Boch, Chinchilla y Las Heras, 2016:15) y de determinó que existen cuatro tipo de entornos en los que el trabajador desarrolla sus actividades (enriquecedor, favorable, desfavorable y contaminante). La clasificación de estos entornos toma en cuenta las políticas aplicadas, la disposición del supervisor y la cultura organizacional. En la siguiente tabla, se recoge un extracto de las características de los referidos entornos

\section{Ver TABLA N02 (al final)}

En el mismo estudio (Estudio IFREI 5.1., 2016), los resultados de Perú demuestran que las empresas tienen un largo camino para adaptarse a las necesidades de conciliación de la vida familiar y laboral de sus trabajadores. La mayoría de empresas peruanas (51\%) mantienen un entorno desfavorable para sus trabajadores lo que trae como consecuencia la poca identificación de los mismos con los objetivos de la organización, al no sentirse apoyados (PAD, 2013). Esto se debe básicamente a los perjuicios que llegan a tener los empresarios, y los propios trabajadores, sobre la necesidad de incluir la variable "familia" en el ámbito laboral, sin considerar que existe evidencia de los efectos negativos relacionados con la falta de previsión de medidas vinculadas al fomento de una adecuada relación familia-trabajador-empresa. La OIT (2009:109) señala entre ellos:

(i) Un menor rendimiento en el puesto de trabajo, debido al estrés relacionado con las tensiones producidas por la falta de conciliación entre familia-trabajo.

Esto se debería a la falta de equidad en la distribución de las labores del hogar por un lado, y la atención de los hijos pequeños por el otro, que se ha puesto en evidencia en la encuesta citada. También podría presentarse en el caso de las madres al volver a sus labores al término del descanso post natal que, si no se acumula, el niño se deja al mes y medio de nacido.

(ii) Se puede afectar el desempeño en la función parental, generar tensión psicológica, irritación frecuente y estrés laboral estrés (50\%).

El cubrir jornadas laborales exigentes o el trabajo de horas extras (sea por cuestiones económicas o por una mal entendida identificación con la empresa) impide que, quienes son padres, dediquen las horas necesarias a la atención a los hijos (exigencia que se incrementa cuando los mismos se encuentran en edad escolar).

(iii) La menor satisfacción laboral y el menor compromiso con la organización (62\%)
Ciertamente un trabajador que no encuentra en su empresa los espacios necesarios para desarrollarse también como padre o madre de familia (por ejemplo, se niegan los permisos para asistir a actuaciones o entrevistas en los colegios, consultas para el médico y demás), termina sintiendo que su trabajo no es adecuadamente valorado, lo que le genera insatisfacción.

(iv) Incremento de la rotación a nivel de unidades productivas y dificultades para contratar y retener trabajadores de mayor nivel de especialización, así como dificultades para la contratación de empleados claves (60\%)

Un trabajador - sobre todo cuando se trata de órganos de línea - puede llegar a preferir un trabajo en el que se le proporcionen mayores facilidades y oportunidades para estar con su familia.

(v) Ausentismo (48\%)

Cuando la empresa no toma en cuenta el entorno familiar de sus trabajadores no puede prever la contingencia del ausentismo de los mismos, que generalmente se presenta cuando los hijos se encuentran en etapa escolar.

De acuerdo a lo señalado por el MTPE (2014), las tensiones entre el trabajo y la vida familiar generan severos problemas para las familias, dado que es frecuente que nos les permitan proporcionar una atención adecuada a niños y niñas, adultos mayores, personas enfermas o que requieren de cuidados especiales y que se prive a los hombres de participar activamente de la crianza de sus hijos y del cuidado de sus familiares, minimizando sus lazos afectivos y su desarrollo integral (8).

Los efectos negativos por no incorporar acciones de RFE son evidentes, sin embargo, pese a lo señalado, se determinó que un $60 \%$ de las empresas carecía de medidas que contemplaran RFE (OIT, 2019:109).

\subsection{Fundamento. Teoría de los círculos concéntricos}

El considerar la relación Familia-Empresa en el ámbito de la RSE tiene su sustento en el principio organizativo que ordena la prioridad de las responsabilidades empresariales en tres círculos concéntricos, tal como lo plantea Melé (citado en Debeljuh, 2016), y distingue responsabilidades primarias, secundarias y terciarias.

(i) Las responsabilidades primarias son inherentes a la actividad específica de la empresa y al cumplimiento de sus fines. Concretamente, los empleados son y deben ser considerados como un grupo de interés primario de toda empresa porque son sujetos con derechos y con demandas legítimas, además son parte fundamental para sacar adelante la organización. 
(ii) Las responsabilidades secundarias, tienen que ver con la mejora de la actividad empresarial en otros grupos relacionados con la empresa.

(iii) Las responsabilidades terciarias no están directamente relacionadas con la actividad específica de la empresa sino que buscan contribuir al bien común junto con otros grupos sociales.

A continuación, siguiendo a Debeljuh y Ordoñez, (2017: 148ss) se detalla el contenido de estas responsabilidades y las medidas concretas que pueden desarrollarse cuando se incorpora la perspectiva de familia en la gestión empresarial, es decir, cuando para el desarrollo de políticas se toma en cuenta el entorno familiar del trabajador.

\section{Ver TABLA N03 (al final)}

Desde esta perspectiva, la RFE se entiende como un modelo integral que busca no solo la conciliación familia y trabajo para los empleados de la empresa (que puedan éstos hacer más compatible su vida familiar y sus obligaciones laborales), sino también construir una cultura que implique tomar a la familia de los colaboradores como un nuevo stakeholder, de manera inclusiva (no discriminatoria) y que tenga un efecto de expansión en todos los miembros de la organización y hacia fuera de ella. (Ordoñez, 2016, p. 57).

Una empresa que tenga como eje de su visión a la persona y sus valores, buscará establecer relaciones con sus empleados que vayan más allá de pagarles un sueldo adecuado. Los considerará en su dimensión familiar y será consiente del papel que asuman en ella.

\subsection{Prejuicios en torno a la implementación de acciones de RFE}

Como se señaló anteriormente, a nivel de los estudios citados, existía un $60 \%$ de empresas que no incluían entre sus acciones de RSC, aquellas que vincularan familia - trabajador - empresa. Cuando se indaga por las razones se encuentra como principal prejuicio el tema de los gastos en los que pudiera incurrir la empresa para implementar estas acciones. Dichos gastos no son entendidos como inversión, sino como sobrecosto para la empresa.

Por otro lado, al no existir una suficiente difusión del tema, sobre todo en lo que se refiere a los beneficios o los perjuicios de su falta de implementación, la alta dirección de la empresa no sabe cómo abordar estas acciones.

Asimismo, algunos empresarios tienen dificultades en asumir las obligaciones legales impuestas, por lo que, las inversiones adicionales (sobre todo si no se sabe cómo afrontarlas) no son prioridad, más aún si estas se enmarcan en el plano de la responsabilidad ética (por tanto, no obligatoria) de la empresa.

Otro aspecto importante es el hecho de pensar que la familia es una realidad exclusivamente privada, y en este sentido, asumir que cualquier problema que le afecte, lo debe resolver sola. Sin embargo, como se ha visto hasta aquí, muchos de los problemas que afronta la familia tienen que ver con la falta de conciliación de la vida laboral y familiar (estrés de los padres, ausencia en casa, poco tiempo de dedicación a los hijos, tensiones con la pareja, etc.). La familia es una realidad social más importante de lo que se piensa, por lo que, una apertura de la empresa para promover políticas de RFE puede hacer la diferencia. No se trata evidentemente de llegar al extremo de inmiscuirse en la vida del trabajador. El enfoque o perspectiva de familia supone que cualquier política - pública o privada - que se implemente, se realiza bajo el principio de subsidiariedad.

Por otro lado, y aunque parezca contradictorio, los trabajadores no suelen demandar estas acciones como prioridad. Esto puede deberse a los altos niveles de competitividad que existe en el mercado laboral (el trabajo en horas extras o jornadas extendidas, disposición inmediata, etc.); además, los trabajadores piensan que solicitar estas reivindicaciones (permisos, licencias, días libres o comisiones) los puede colocar en situación de desventaja frente a los demás (no ser considerado para ascensos, por ejemplo) o puede traer consecuencias negativas en su desarrollo profesional.

Esta barrera tiene especial relación con la cultura de la organización pues, de acuerdo a la encuesta IFREI 5.1. (Boch, Chinchilla y Las Heras, 2016) la mera existencia de políticas de conciliación de la vida familiar y laboral no garantiza que los trabajadores las utilicen debido a que es posible que la cultura de la empresa no las asuma adecuadamente.

También es interesante saber - de acuerdo a los resultados de este estudio - que la percepción de los colegas con respecto a los futuros padres o madres que toman sus permisos legales, es negativa, de allí que se hable, por ejemplo del mobbing maternal, entendido como "El acoso laboral sistemático por razón de sexo indisolublemente unido a la condición de la maternidad, ya sea potencial o existente, con consecuencias físicas y psicológicas que afectan especialmente a la mujer embarazada, pero también tiene repercusión durante la lactancia o cuando se tiene hijos en edad preescolar (Peña, 2016:8). Si bien no existen referencias estadísticas del grado de afectación del mobbing maternal en Perú, podemos hacer referencia que en España, por ejemplo, se dice que el $32 \%$ de las mujeres 
sufre mobbing durante su embarazo y un $50 \%$ después del parto, especialmente después de su baja por maternidad. En total un $82 \%$ de las mujeres gestantes y madres españolas sufren discriminación laboral (Peña, 2016:8).

Un detalle que no puede pasar desapercibido es que se asume que la conciliación de la vida familiar y laboral solo es un "problema de mujeres". Una muestra de ello es que las políticas públicas, en su mayoría, están enfocadas en ellas. Esto, aunque paradójicamente, acrecienta la brecha que existe entre el modo como se concibe la corresponsabilidad y lo que realmente implica: asumir las tareas del cuidado de los hijos y del hogar desde su particular modo de ser (masculino y femenino) con respeto, consideración y equidad, tiene su explicación en el hecho que "ante una mayor presencia de niños en el hogar la mujer se vería desmotivada en participar en el mercado laboral, pues optará por dedicar su tiempo al cuidado de ellos" (MTPE, 2016:60). Por ello, a nivel privado, se deben ponderar las acciones equitativas para trabajadores y trabajadoras, sin dejar de tener en cuenta las especiales diferencias biológicas.

\subsection{Los efectos favorables de la RFE}

Los beneficios que mencionamos a continuación condensan los resultados de diversos estudios realizados tanto para medir directamente el impacto de la RFE en las empresas, como aquellos dirigidos a medir el impacto de la implementación de políticas de conciliación de la vida familiar y laboral. Así, la RFE le permite a la empresa:

(i) Mejorar el clima laboral: Los trabajadores que se sienten respaldados por su empresa, laboran más tranquilos, resuelven necesidades relacionadas con la calidad de vida y logran un mejor manejo del estrés. Las empresas que generan entornos familiarmente responsables tienen niveles de satisfacción de equilibrio familiar laboral del $146 \%$ comparado con los que trabajan en entornos difíciles.

(ii) Incrementar beneficios económicos: debido a lo anterior, son varias las experiencias que dan cuenta que la aplicación de medidas RSE mejoran la productividad. Así por ejemplo en Chile se notó una mejora de la producción de $11 \%$ a $16 \%$ en las empresas.

(iii) Mejorar la imagen pública: al perfilarse como una empresa que promueve la igualdad de oportunidades y reconoce el valor de la familia. Existe una gran cantidad de empresas que apelan a la unión familiar y a identidad familiar para realizar su publicidad. (iv) Retener a las personas con talento: y aumentar la productividad de las empresas por medio de la disminución de rotación o las ausencias, y la mejora en la estabilidad y la motivación. (Ordoñez, 2016:56). De acuerdo con los datos del Estudio IFREI (2016), los ejecutivos que trabajan en empresas tipo $D$, contaminantes, manifiestan una intención de dejar la compañía de 209\% comparado con los que trabajan en una empresa familiarmente responsable, tipo $\mathrm{A}$.

(v) Finalmente, y tal como sucede con la RSC (que se convierte en un factor importante para el cumplimiento de los ODS), puede verse que cada uno de los Objetivos de Desarrollo Sostenible está vinculado con la familia. Morales (2016) señala que cuando hablamos de poner fin a la pobreza y al hambre, de salud y bienestar, de educación de calidad, de igualdad de género, de mejorar el ambiente, de trabajo decente, de reducción de las desigualdades y de instituciones sólidas sin dudas estamos hablamos de la familia. La primera institución, dentro de un Estado. La familia es el primer lugar de socialización de niñas y niños y parte fundamental de la sociedad (p.71).

Los beneficios de implementar acciones de RSC son mayores que los prejuicios que se tienen de la misma. Por ello, es importante que el sector empresarial se involucre y decida incorporar el enfoque de familia en la gestión de la empresa, de acuerdo a sus posibilidades concretas.

\section{RESPONSABILIDAD FAMILIAR EMPRESARIAL DESDE LA PERSPECTIVA JURÍCA}

\subsection{Marco jurídico aplicable a la Responsabilidad Familiar Empresarial}

Si bien el presente trabajo se enfoca en plantear la incorporación del enfoque de familia en la gestión empresarial, es decir, en el ámbito privado. Consideramos importante referirnos al marco jurídico que puede amparar, fomentar y promover las acciones de RFE.

En este sentido, al derecho le corresponde regular el contenido del Enfoque de Familia. Si bien actualmente no contamos con una norma que lo defina, si se cuenta con el marco constitucional que le sirve de fundamento (El Art. 4 de la CPP). Sin perjuicio de ello, definiremos el Enfoque de Familia como aquel que establece que tanto las políticas públicas y privadas, como de los programas de trabajo de las organizaciones de la sociedad civil, deben considerar que las estructuras y dinámicas de funcionamiento de las familias son fundamentales para el desarrollo y el bienestar de los individuos y de la 
sociedad. En otras palabras, se entiende el papel de la familia en su real dimensión. No solo como medio del que se vale el Estado para atender a sus ciudadanos, ni como el interlocutor entre el Estado y sus miembros; sino como la institución natural más importante de las sociedades democráticas.

En el marco supranacional, el Enfoque de Familia se sustenta en el Convenio 156 de la OIT, Convenio sobre los trabajadores con responsabilidades familiares (ratificado por el Perú mediante Resolución Legislativa № 24508) que indica en el numeral 1 de su artículo 3 que, con miras a crear la igualdad efectiva de oportunidades y de trato entre trabajadores y trabajadoras, cada miembro deberá incluir entre los objetivos de su política nacional la permisión de que las personas con responsabilidades familiares que desempeñen o deseen desempeñar un empleo ejerzan su derecho a hacerlo sin ser objeto de discriminación y, en la medida de lo posible, sin conflicto entre sus responsabilidades familiares y profesionales.

El Acuerdo Nacional (2002) señala como Décima Sexta Política Pública de Estado "El fortalecimiento de la familia, protección y promoción de la niñez, la adolescencia y la juventud", a partir del cual se asumen los siguientes compromisos

(i) Fortalecer a las familias para el desarrollo integral de la persona

(ii) Erradicar la violencia familiar

(iii) Promover la convivencia pacífica y la cultura de paz En el mismo sentido, el Art. $3^{\circ}$ del Decreto Legislativo 1408 reconoce la corresponsabilidad como un enfoque transversal para el fortalecimiento de la familia y señala que "la distribución igualitaria de las tareas domésticas y de cuidado entre los hombres y las mujeres al interior de las familias es un elemento clave para el desarrollo de las personas y de las familias en sí misma, y consideran las capacidades, dificultades de la tarea y el tiempo de cada cual de acuerdo a su edad y madurez, propiciando el desarrollo de la autonomía de sus integrantes y la mejora en las interacciones del medio familiar. La corresponsabilidad familiar implica además que tanto el hombre como la mujer son responsables del mantenimiento económico del hogar".

Por su parte el Art. $8^{\circ}$ del Decreto Legislativo 1443 (que modifica el DL 1408) señala que son obligaciones del Estado hacia la familia, en lo que concierne a la RFE:

(i) Promover responsabilidades familiares compartidas entre los integrantes de las familias, en términos de igualdad de género y el respeto a los derechos humanos (8.2)

(ii) Implementar programas, servicios especializados y políticas en beneficio de las familias que se encuentran en situación de vulnerabilidad, priorizando a las familias que experimentan situaciones de violencia, pobreza extrema, pobreza o riesgo social, así como de las familias jefaturadas por mujeres (8.4)

(iii) Desarrollar políticas públicas que tienen en consideración el entorno familiar (8.7)

(iv) Dictar disposiciones sociales, económicas, tributarias y laborales, de apoyo y promoción de la familia (8.9)

(v) Promover el establecimiento de servicios de cuidado infantil en los centros laborales públicos y privados, así como en el ámbito regional y municipal programas, proyectos y servicios especializados para el fortalecimiento de la familia (8.11)

(vi) Velar por el respeto de las ocho horas laborales en las instituciones públicas y privadas para garantizar el tiempo suficiente y necesario para que los padres y madres puedan compartir más tiempo con sus hijos (8.12)

Otra norma que sirve como referencia para le RFE es la "Guía de buenas prácticas en materia de conciliación del trabajo y la vida familiar y personal" aprobada por Resolución Ministerial № 048-2014-TR que busca orientar "a los empleadores en la aplicación de medidas destinadas a promover la no discriminación e igualdad de oportunidades, tanto en el proceso de colocación laboral como en el lugar de trabajo, lo cual apoyará en mejorar la gestión de los recursos humanos en las empresas; así como, en la utilización eficaz de sus competencias y de las relaciones de trabajo". Los objetivos perseguidos por la guía se plantean en consonancia con la realidad descrita en el presente artículo, en tanto busca:

(i) Promover entre empleadores y trabajadores el cumplimiento de la normativa sobre igualdad de oportunidades y la no discriminación así como la adopción de prácticas voluntarias o acuerdos que permitan la conciliación entre el trabajo y la vida familiar y personal.

(ii) Ayudar a los empleadores a desarrollar acciones que impulsen el incremento sostenido de la productividad mediante la mejora del desempeño laboral, la prevención de enfermedades profesionales derivadas de la tensión entre la vida laboral y la vida familiar y personal, la disminución del ausentismo, entre otros.

(iii) Difundir entre los trabajadores y sus organizaciones la importancia de conciliar el trabajo y la vida familiar y personal, y promover la inclusión de medidas con este objetivo en la negociación colectiva. 
(iv) Ayudar a los profesionales encargados de la gestión de personal y a los asesores de las empresas que fomenten la conciliación del trabajo y la vida familiar y personal, así como la prevención y erradicación de la discriminación en base al género.

La Ley 28983, Ley de igualdad de oportunidades entre mujeres y hombres prevé como lineamientos del Poder ejecutivo, gobiernos regionales y locales que se incluya entre los derechos laborales (...) la armonización de las responsabilidades familiares y laborales. (Art. $6^{\circ}$, inc. f.) Corresponde entonces al ordenamiento jurídico implementar y reglamentar las normas de conciliación de la vida laboral y familiar considerando el marco de la libertad de empresa y la libre iniciativa privada, brindando los incentivos correspondientes a fin que el empleador no experimente un perjuicio material que no se compense con los resultados obtenidos.

\subsection{Acciones de RFE y su tratamiento normativo}

Cuando se pretende trasladas las RFE de un plano teórico a uno más concreto (o práctico) nos encontramos con que no existe un modelo uniforme para el desarrollo ordenado y sistemático de dichas acciones por ello, se apela a la consideración de la realidad de cada empresa.

Uno de los modelos que presenta la doctrina parte de considerar tres dimensiones en la empresa: las políticas, el apoyo del supervisor y la cultura organizativa, a partir de las cuales se pueden estructurar las acciones de RFE (Boch, Chinchilla y Las Heras, 2016).

Así, el balance de la vida laboral y familiar del trabajador depende mucho de que la RFE se haya incorporado como valor en la empresa, pues solo de esta manera, la línea directiva se orientará a construir un entorno favorable para el trabajador.

Otro modelo sugiere agrupar las medidas en grupos relativos a (i) liderazgo y estilo de dirección, (ii) calidad en el empleo, (iii) flexibilidad temporal y espacial, (iv) apoyo a la familia de los empleados, (v) desarrollo profesional (vi) igualdad de oportunidades; para distinguir el tipo de acciones que desarrollará y decidir a qué aspecto se le da mayor relevancia en la empresa. En cualquier caso, lo común en ambos modelos es que se requiere involucrar a la alta dirección de la empresa (con ello se involucra la cultura organizacional), conciliar la vida familiar y laboral, apoyar el desarrollo familiar del trabajador, garantizar la igualdad de oportunidades y derechos humanos, comunicar adecuadamente dichas medidas y no discriminar entre las obligaciones legales y aquellas que - al no serlo - forman parte del compromiso ético de la empresa.
A continuación, mencionamos algunas acciones que entran en la categoría de políticas de RFE tomando en cuenta - como criterio ordenador - los aspectos enumerados en el párrafo precedente. En la tabla, se hace referencia también a aquellas acciones que, al estar amparadas en una norma legal, se convierten en políticas públicas con enfoque de familia. En este caso, se sugiere que las empresas se esfuercen en aplicarlas incluso si no ingresaran en la categoría de "exigibles" para éstas (por ejemplo, cuando su obligatoriedad requiere un número mínimo de trabajadores).

Se puede apreciar también, que el legislador peruano ha dejado un amplio margen al empresario para decidir las acciones de RFE que puede implementar de manera voluntaria, lo que no es óbice para que, desde el gobierno, se implementes acciones de promoción y sensibilización para los empresarios en esta materia.

Por otro lado, es importante señalar que, además del compromiso de la alta dirección de la empresa, son los trabajadores quienes tienen que involucrarse en la propuesta de acciones RSE pues, teniendo en cuenta la diversidad de realidades familiares, se debe buscar en consenso, aquellas acciones que beneficien a la mayoría.

Ver TABLA N04 (al final)

\section{Conclusiones}

Al culminar el presente trabajo, podemos concluir lo siguiente:

Que la importancia de la familia radica no solo en que, con el cumplimiento de sus fines contribuye al adecuado desarrollo del tejido social, sino que es el ámbito primario de desarrollo y felicidad del ser humano.

Que una adecuada atención a la realidad familiar parte de considerar que la familia es un sujeto social, pasible de protección de la sociedad y del Estado. Para llevar a cabo de manera efectiva dicha protección, se debe incorporar la perspectiva de familia, tanto en las políticas públicas, como en la actividad privada.

Que las empresas tienen el deber ético de considerar la dimensión familiar de las personas que integran la organización, para ello, debe incorporar la conciliación de la vida laboral y familiar, desde la perspectiva de la corresponsabilidad, como una variable estratégica y de gestión integral.

Que el éxito de las acciones de Responsabilidad Familiar Empresarial depende en gran medida de la actitud que asuman los directivos en la empresa (líderes y supervisores), que a su vez influye en toda la cultura 
organizacional, así como de la comunicación efectiva que se haga de dichas medidas.

Que aún son muy pocas las empresas - a nivel mundial y en Perú - que han incorporado la perspectiva de familia para desarrollar acciones de RFE, pues se tienen algunos prejuicios relacionados con los costos que puede generar la implementación de políticas de esta naturaleza y no se tienen a la vista las ventajas de desarrollar acciones en favor de la familia como puede ser la mejora del clima laboral, la fidelización de los trabajadores, la mayor disposición para desarrollar sus tareas, y el mejoramiento de la producción.

Que, el ordenamiento jurídico peruano contiene normas que pueden orientar la acción de las empresas hacia la conciliación de la vida laboral y familiar, sin embargo, ese es solo uno de los aspectos de la RFE. Lo demás queda a cargo de la disposición de los empresarios y del grado de compromiso con sus trabajadores y sus familias

\section{Bibliografía}

Barbachan, M. (2017). La Responsabilidad Social Empresarial en el Perú: Desafíos y Oportunidades. INNOVAG - Revista de estudiantes de la Facultad de Gestión y Alta Dirección, (2), Lima, Perú: PUCP. Recuperado de http://revistas.pucp.edu.pe/index.php/innovag/ article/view/18749/18989

Bosh, M.; Chinchilla, N.; Las Heras, M. (2016). Estudio de Responsabilidad Social Corporativa - IFREI 5.1. Recuperado de https://www.ese.cl/ese/tipo-dedocumento/estudios/responsabilidad-familiarcorporativa-estudio-ifrei-1-5-2017/2018-0514/105102.html

Burgos, J.M. (2004). Diagnóstico sobre la familia. Madrid, España: Palabra

Charro, P.; Espinoza, J. (2015). Cuestiones actuales de derecho del trabajo. Un estudio desde las dos orillas. Madrid, España: Dykinson

Debeljuh, P.; Ordoñez. M. (2014). Círculos concéntricos de responsabilidad Principio organizativo. En Debeljuh, P.; Ordoñez, M. Hacia una responsabilidad compartida: familia, empresa y sociedad: Guía de buenas prácticas (pp. 145245). 1era ed., Buenos Aires, Argentina: Baur. Recuperado de https://www.iae.edu.ar/es/Landings/Confye/flip book2017/index.html

De las Casas, O. (2010). La responsabilidad social empresarial. Recuperado de http://www.infocapitalhumano.pe/recursos- humanos/alerta-legal/la-responsabilidad-socialempresarial/

Diario Gestión. (2016). Conozca la opinión de las empresas peruanas sobre la responsabilidad social. Diario Gestión. Recuperado de https://gestion.pe/economia/empresas/conozcaopinion-empresas-peruanas-responsabilidadsocial-115619?foto $=8$

Donati, P. (2014). La política de la familia. Por un welfare relacional y subsidiario, Santiago de Chile, Chile: Ediciones Universidad Católica de Chile.

Echaiz, D. (Coord.) (2010). Instituciones de Derecho Empresarial. Lima, Perú: APECC

Fundación Más Familia. (2018). Iniciativa EFR, (Acceso 22.10.2018) https://www.masfamilia.org/modelo-efr-empresa\# Forum Empresa (2009). Estado de la Responsabilidad Social empresarial en América Latina bajo la mirada de ejecutivos de empresas de Latinoamérica. Santiago de Chile. Chile: Forum Empresa

Peña Gallo, M. (2016). El mobbing maternal: una forma de discriminación laboral contra la mujer en Europa El caso de mujeres gestantes y madres en España y Reino Unido. Barcelona, España: Instituto de Derechos Humanos de Catalunya. Recuperado https://www.idhc.org/arxius/ajudes-

formacio/1467892046-PE\%C3\%91A MLuisa.pdf Idrovo, S.; Debeljuh, P. (2014). La responsabilidad desde la familia Vida y trabajo: el cuidado como responsabilidad personal. En Debeljuh, P.; Ordoñez, M., Hacia una responsabilidad compartida: familia, empresa y sociedad: Guía de buenas prácticas (pp. 33-46). 1era ed., Buenos Aires, Argentina: Baur. Recuperado

https://www.iae.edu.ar/es/Landings/Confye/flipbo ok2017/index.html

INDECOPI (2010). Norma técnica de Responsabilidad Social. Recuperado de https://unaaa.edu.pe/unaaa/principal/docs/carta desarrollo sostenible/7Responsabilidad Social Un iversitaria/ISO_26000.pdf

INEI (2007) Tipos y Ciclos de vida de los hogares. Recuperado

https://www.inei.gob.pe/media/MenuRecursivo/p ublicaciones digitales/Est/Lib0870/libro.pdf ISO (2010). ISO 26000. Visión general del proyecto. Recuperado de https://www.iso.org/files/live/sites/isoorg/files/arc hive/pdf/en/iso 26000 project overview-es.pdf

Libertad y Desarrollo (2007). Encuesta de libertad y desarrollo percepción de la importancia de la familia y el rol de los padres. Recuperado 
https://lyd.org/other/files mf/encuestafamilalyd 07pdf.pdf

Marín Rives, L.; López Davis, S. (2016). Empresa, Derechos Humanos y RSC. En: Meseguer Sánchez, J.; Avilés Hernández, M. (Directores); Nicolás Guardiola, J.; Giner Alegría, C. (Coordinadores). Empresas, derechos humanos y RSC. Una mirada holística desde las ciencias sociales y jurídicas. 185-196 Cizur Menor, España: Thomson Reuters - Aranzadi

Martínez (2015). Anuario Corresponsables. Recuperado de

http://publicaciones.corresponsables.com/publica tion/e60c5e1/mobile/

Marquina, P.; Et.Al. (2011). Diagnóstico de a responsabilidad Social en Organizaciones Peruanas. Una aproximación interdisciplinaria y multidisciplinaria, Lima, Perú: Perú 2021-PUCP

Ministerio de la Mujer y Poblaciones Vulnerables (2014). Plan Nacional de Fortalecimiento a las Familias, 2014-2017, Lima, Perú: MIMP

Ministerio de la Mujer y Poblaciones Vulnerables (2016). Plan Nacional de Fortalecimiento a las Familias, 2016-2021, Lima, Perú: MIMP.

Ministerio de Trabajo y promoción del empleo (2014). Guía de buenas prácticas en materia de conciliación del trabajo y la vida familiar y personal. Lima, Perú: Dirección General de derechos fundamentales y seguridad y salud en el trabajo MTPE

Ministerio de trabajo y promoción del empleo. (2015). 1er. Foro Nacional de Responsabilidad Social Empresarial. Perú Responsable. Lima, Perú: Programa Nacional de promoción de la responsabilidad Familiar Empresarial - MTPE. Recuperado

http://www.trabajo.gob.pe/PERU RESPONSABLE/ pdf/responsabilidad SE.pdf

Ministerio de Trabajo y promoción del empleo (2016). Informe anual 2016. Las mujeres en el mercado laboral peruano. Lima, Perú: Dirección general de promoción del empleo - MTPE

Miró, J. La función económica y social de la familia (2008). En Contreras, F. (Edit.), Debate sobre el concepto de familia, 143-166, Madrid, España: Dykinson - CEU Ediciones.

Morales, V. (2014). La responsabilidad desde la sociedad. La familia, pilar de las políticas sociales y públicas. En Debeljuh, P.; Ordoñez, M. Hacia una responsabilidad compartida: familia, empresa y sociedad: Guía de buenas prácticas, 67-82, 1era ed., Buenos Aires, Argentina: Baur. Recuperado de
https://www.iae.edu.ar/es/Landings/Confye/flipb ook2017/index.html

OIT (2009). Hacia nuevas formas de conciliación con corresponsabilidad social. Recuperado de https://www.ilo.org/wcmsp5/groups/public/--dgreports/---

gender/documents/publication/wcms_111376.pd f

Ordoñez, M. (2014). La responsabilidad desde la empresa. En Debeljuh, P.; Ordoñez, M.. Hacia una responsabilidad compartida: familia, empresa y sociedad: Guía de buenas prácticas, 49-66. 1era ed., Buenos Aires, Argentina: Baur. Recuperado de https://www.iae.edu.ar/es/Landings/Confye/flipb ook2017/index.html

PAD (2013). Lo que se nos viene: ¿Responsabilidad Familiar Corporativa? Recuperado de https://pad.edu/2013/03/25/lo-que-se-nos-vieneresponsabilidad-familiar-corporativa/

Pérez Carrillo, E. (2012) Empresa socialmente responsable y crecimiento empresarial sostenible. En: Fernández-Albor Baltar, Á. (Director); Pérez Carrillo, E. (Coordinadora). Empresa responsable y crecimiento sostenible: aspectos conceptuales, societarios y financieros, 25-57. Cizur Menor, España: Thomson Reuters - Aranzadi

Pérez, L. (2018). Cuidémonos: Hacia la coresponsabilidad en los cuidados. X Convención nacional de familias. Lima, Perú: MIMP

Gobierno de España (2015). Plan Integral de Apoyo a la Familia. Recuperado de http://www.bienestaryproteccioninfantil.es/imag enes/tablaContenidos03SubSec/4679 d PIAF2015-2017.pdf

Pliego, F.; Castro, R. (2015) Tipos de familia y bienestar de niños y adultos. Arequipa, Perú: UCSP.

Torres Tafur, C. (2014). La costumbre en el ordenamiento jurídico peruano. Un análisis desde la jurisprudencia. 33-42. En: Charro Baena, P.; Espinoza Escobar, J. (Dir.) Cuestiones actuales de derecho de trabajo. Un estudio desde las dos orillas. Madrid, España: Dykinson.

Universidad Católica San Pablo (2017) IV Barómetro de la Familia. Estado de la Familia en Arequipa. Arequipa, Perú: UCSP 


\section{GRÁFICOS Y TABLAS}

TABLA $N^{\circ} 01$

HORAS DE DEDICACIÓN A DIVERSAS ACTIVIDADES POR SEXO

\begin{tabular}{|c|c|c|}
\hline \multirow[t]{2}{*}{ ACTIVIDAD } & \multicolumn{2}{|c|}{ HORAS DE DEDICACIÓN } \\
\hline & MUJERES & VARONES \\
\hline Cuidado algún miembro del hogar & 16.47 & 8.55 \\
\hline Familia, sociabilidad y tiempo libre & 15.16 & 14.48 \\
\hline Actividad culinaria & 13.43 & 4.02 \\
\hline Cuidado de bebés y niños & 13.43 & 5.49 \\
\hline Aseo de la vivienda & 6.38 & 3,29 \\
\hline Actividades de tiempo libre & 14.28 & 18.46 \\
\hline Atención necesidades personales & 69.26 & 67.58 \\
\hline Actividad educativa & 34.52 & 36.37 \\
\hline Actividades de reparación & 2.8 & 3.33 \\
\hline Compras para el hogar & 3.37 & 2.38 \\
\hline
\end{tabular}

Fuente INEl: Encuesta Nacional de Hogares, 2014

TABLA N 02

MODELOS DE ENTORNOS EMPRESARIALES

\begin{tabular}{|c|c|c|c|}
\hline ENTORNO & DESCRIPCIÓN & $\begin{array}{l}\text { \% EMP. } \\
\text { PERÚ }\end{array}$ & CARACTERÍSTICAS \\
\hline ENRIQUECEDOR & $\begin{array}{l}\text { Muy positivo y favorece } \\
\text { la integración trabajo- } \\
\text { familia-vida personal } \\
\text { sistemáticamente. Estos } \\
\text { ámbitos se enriquecen } \\
\text { mutuamente, logrando } \\
\text { un alto nivel de } \\
\text { satisfacción } \\
\text { compromiso }\end{array}$ & $10 \%$ & $\begin{array}{l}\text { - Existen políticas formales bien definidas, } \\
\text { implementadas, y aceptadas por todos. } \\
\text { - Se respetan las decisiones de cada persona } \\
\text { en relación a su integración familia, trabajo } \\
\text { y vida personal. } \\
\text { - Los supervisores comprenden las } \\
\text { demandas familiares de sus colaboradores } \\
\text { y procuran facilitar la conciliación. } \\
\text { - Los valores que definen la cultura } \\
\text { promueven un clima de trabajo } \\
\text { enriquecedor que favorece la } \\
\text { Responsabilidad Familiar Corporativa. }\end{array}$ \\
\hline FAVORABLE & $\begin{array}{l}\text { El entorno laboral facilita } \\
\text { la integración trabajo- } \\
\text { familia-vida personal. } \\
\text { Estos ámbitos se } \\
\text { enriquecen de forma } \\
\text { ocasional, pudiendo } \\
\text { surgir conflictos que los } \\
\text { propios colaboradores } \\
\text { han de afrontar } \\
\text { personalmente }\end{array}$ & $34 \%$ & $\begin{array}{l}\text { - Existen políticas formales aunque no } \\
\text { siempre están suficientemente definidas ni } \\
\text { aceptadas por todos. } \\
\text { - Se respetan de forma ocasional las } \\
\text { decisiones de cada persona en relación a su } \\
\text { integración familia, trabajo y vida personal. } \\
\text { - Los managers asumen en un nivel } \\
\text { aceptable las demandas familiares de sus } \\
\text { colaboradores y facilitan la conciliación en } \\
\text { determinadas circunstancias. } \\
\text { - Los valores que definen la cultura } \\
\text { promueven un clima de trabajo favorable } \\
\text { hacia la Responsabilidad Familiar } \\
\text { Corporativa }\end{array}$ \\
\hline
\end{tabular}




\begin{tabular}{|c|c|c|c|}
\hline DESFAVORABLE & $\begin{array}{l}\text { El entorno laboral } \\
\text { dificulta ocasionalmente } \\
\text { la integración trabajo- } \\
\text { familia-vida personal. } \\
\text { Estos ámbitos entran de } \\
\text { forma habitual en } \\
\text { conflicto, generando en } \\
\text { los colaboradores la } \\
\text { percepción de falta de } \\
\text { apoyo de la organización, } \\
\text { estrés e insatisfacción }\end{array}$ & $51 \%$ & $\begin{array}{l}\text { - Las políticas formales se implementan de } \\
\text { forma limitada y tienen escaso impacto en } \\
\text { las personas. } \\
\text { - Los managers dificultan el equilibrio entre } \\
\text { trabajo, familia y vida personal de sus } \\
\text { colaboradores. } \\
\text { - Los valores que definen la cultura no } \\
\text { promueven el clima adecuado para el } \\
\text { desarrollo de la Responsabilidad Familiar } \\
\text { Corporativa. } \\
\text { - Como resultado no se logra el nivel de } \\
\text { compromiso requerido por la organización }\end{array}$ \\
\hline CONTAMINANTE & $\begin{array}{l}\text { El entorno laboral } \\
\text { dificulta } \\
\text { sistemáticamente la } \\
\text { integración entre trabajo, } \\
\text { familia y vida personal. } \\
\text { Estos ámbitos entran de } \\
\text { forma sistemática en } \\
\text { conflicto, generando en } \\
\text { los colaboradores } \\
\text { insatisfacción y un alto } \\
\text { grado de estrés, } \\
\text { favoreciendo la } \\
\text { desmotivación y el deseo } \\
\text { de dejar la empresa }\end{array}$ & $5 \%$ & $\begin{array}{l}\text { - Las políticas existentes no están } \\
\text { implementadas. } \\
\text { - Los managers no están comprometidos } \\
\text { con la flexibilidad. } \\
\text { - Los valores que definen la cultura dificultan } \\
\text { el clima adecuado para el desarrollo de la } \\
\text { Responsabilidad Familiar Corporativa. } \\
\text { - Como resultado se generan problemas en } \\
\text { las relaciones interpersonales, limitando el } \\
\text { rendimiento y el compromiso de los } \\
\text { colaboradores }\end{array}$ \\
\hline
\end{tabular}

Elaboración propia.

Fuente: Estudio IFREI 5.1. (2016)

TABLA N ${ }^{\circ} 03$

NIVELES DE RESPONSABILIDAD EMPRESARIAL

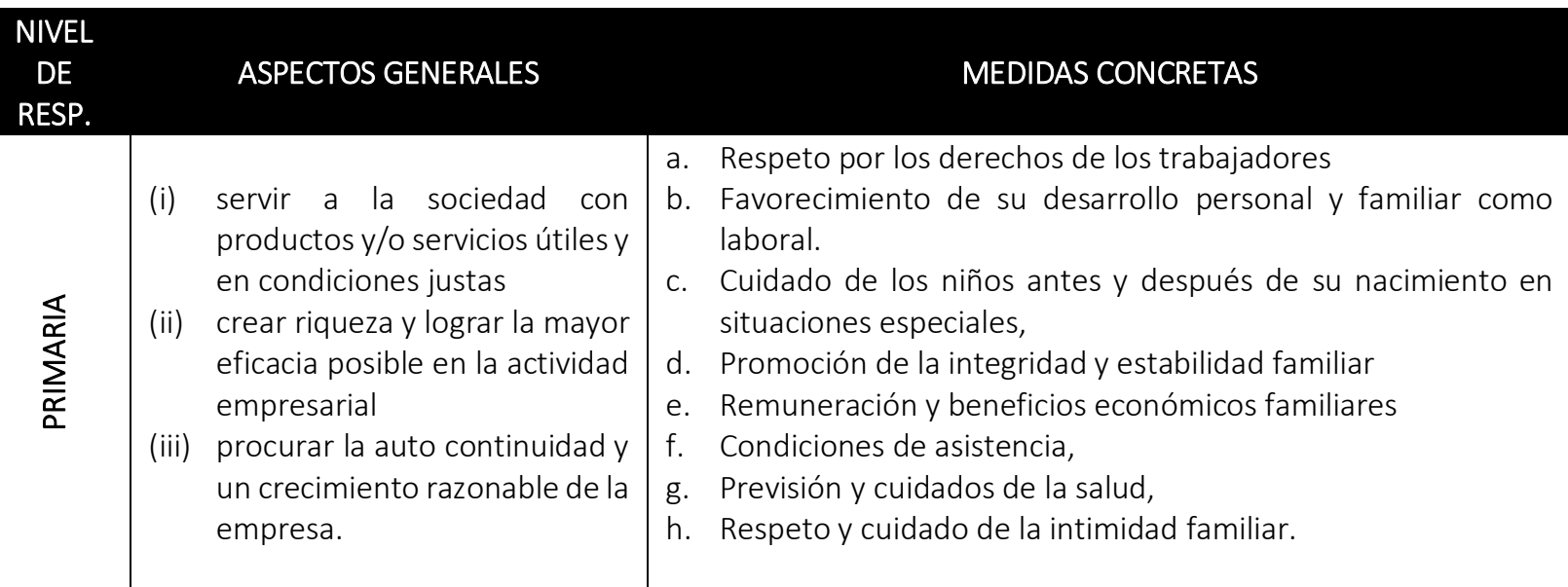




\begin{tabular}{|c|c|c|}
\hline $\begin{array}{l}\text { 市 } \\
\text { 玄 } \\
\text { 号 } \\
\text { 岃 }\end{array}$ & $\begin{array}{l}\text { Iniciativas de la acción empresarial } \\
\text { en los grupos sociales } \\
\text { interdependientes con la empresa, } \\
\text { siempre dentro del ejercicio de la } \\
\text { actividad específica de la empresa. } \\
\text { Tienen su fundamento en la } \\
\text { exigencia ética de buscar lo mejor y } \\
\text { no solo evitar aquello que es } \\
\text { inaceptable. }\end{array}$ & $\begin{array}{l}\text { Respecto a los trabajadores: } \\
\text { a. Fomento del tiempo para estar en familia } \\
\text { b. Impulso de una adecuada gestión del uso del tiempo } \\
\text { c. Promoción de acciones para el desarrollo profesional de las } \\
\text { mujeres y su articulación con la vida familiar } \\
\text { d. Fomento del compromiso y ejemplo de la dirección y de los } \\
\text { jefes respecto a la integración trabajo-familia } \\
\text { e. Formación de un liderazgo familiarmente responsable } \\
\text { Respecto de otros grupos de interés: } \\
\text { a. Promoción del respeto y garantía de los derechos de la familia } \\
\text { en los accionistas } \\
\text { b. Promoción del respeto y garantía de los derechos de la familia } \\
\text { en la cadena de valor } \\
\text { c. Uso del marketing y la publicidad para promover la } \\
\text { integración trabajo y familia en la sociedad y en los } \\
\text { consumidores } \\
\text { d. Articulación con asociaciones empresariales y sindicales. }\end{array}$ \\
\hline 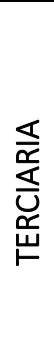 & $\begin{array}{l}\text { Contribuyen al bien común junto } \\
\text { con otros grupos sociales }\end{array}$ & $\begin{array}{l}\text { a. Ayuda y beneficios extra-salariales o sociales } \\
\text { b. Reconocimiento y apoyo a los estudios de los hijos } \\
\text { c. Asesoramiento y gestión de asuntos sociales para empleados } \\
\text { y familiares } \\
\text { d. Actividades en la empresa con miembros de la familia } \\
\text { e. Voluntariado corporativos sumando a las familias, } \\
\text { f. Articulación y generación de políticas públicas que difundan y } \\
\text { promuevan la integración trabajo-familia }\end{array}$ \\
\hline
\end{tabular}

\section{Elaboración propia}

Fuente: Hacia una responsabilidad compartida: familia, empresa y sociedad: Guía de buenas prácticas (Debeljuh y Ordoñez, 2017).

\section{TABLA N 04 \\ ACCIONES DE RESPONSABILIDAD FAMILIAR EMPRESARIAL Y SU TRATAMIENTO NORMATIVO}

\begin{tabular}{|c|c|c|}
\hline ASPECTO & ACCIÓN & NORMA LEGAL (Perú) \\
\hline \multirow{3}{*}{$\begin{array}{l}\text { Compromiso } \\
\text { de alta } \\
\text { dirección }\end{array}$} & $\begin{array}{l}\text { Capacitación y sensibilización } \\
\text { para asumir acciones de RFE }\end{array}$ & \\
\hline & $\begin{array}{l}\text { Grupos de discusión para } \\
\text { identificar necesidades de } \\
\text { conciliación y sugerir medidas a } \\
\text { las empresas. }\end{array}$ & \\
\hline & $\begin{array}{l}\text { Apoyo emocional. } \\
\text { Involucramiento de personal de } \\
\text { dirección a fin de implantar } \\
\text { cultura organizacional. }\end{array}$ & \\
\hline $\begin{array}{l}\text { Conciliación } \\
\text { vida laboral y } \\
\text { familiar }\end{array}$ & $\begin{array}{l}\text { Protección por despido en caso } \\
\text { de embarazo o parto. }\end{array}$ & $\begin{array}{l}\text { Decreto Legislativo } 728 \text { - Ley de Productividad y } \\
\text { Competitividad Laboral, modificado por la Ley } 30367 \text { - } \\
\text { Ley que protege a la madre trabajadora contra el despido } \\
\text { arbitrario y prolonga su periodo de descanso } \\
\text { La norma señala en su artículo } 29^{\circ} \text { que es nulo el despido } \\
\text { que tenga por motivo: }\end{array}$ \\
\hline
\end{tabular}




\begin{tabular}{|c|c|}
\hline & $\begin{array}{l}\text { e) el embarazo, el nacimiento y sus consecuencias o la } \\
\text { lactancia, si el despido se produce en cualquier } \\
\text { momento del periodo de gestación o dentro de los } 90 \\
\text { (noventa) días posteriores al nacimiento. Se presume } \\
\text { que el despido tiene por motivo el embarazo, el } \\
\text { nacimiento y sus consecuencias o la lactancia, si el } \\
\text { empleador no acredita en estos casos la existencia de } \\
\text { causa justa para despedir. } \\
\text { Esta circunstancia es aplicable siempre que el empleador } \\
\text { hubiere sido notificado documentalmente del embarazo } \\
\text { en forma previa al despido (la obligación es de la } \\
\text { trabajadora) y no enerva la facultad del empleador de } \\
\text { despedir por causa justa". }\end{array}$ \\
\hline & $\begin{array}{l}\text { Ley } 26644 \text { que Precisa el goce del derecho de descanso } \\
\text { pre-natal y post-natal de la trabajadora gestante } \\
\text { DS No005-2011-TR - Reglamento }\end{array}$ \\
\hline Licencia por maternidad & $\begin{array}{l}\text { Ley } 27606 \text { que modifica la Ley } 26644 \text { y establece la } \\
\text { extensión del descanso postnatal en los casos de } \\
\text { nacimiento múltiple } \\
\text { La madre trabajadora tiene derecho a } 49 \text { días de } \\
\text { descanso pre natal y } 49 \text { días de descanso post natal que } \\
\text { pueden ser acumulables por decisión de la madre y } \\
\text { previo informe médico que certifique que la } \\
\text { postergación del descanso pre-natal no afectaría en } \\
\text { modo alguno a la trabajadora gestante o al concebido. } \\
\text { La decisión deberá ser comunicada al empleador con una } \\
\text { antelación no menor de dos meses a la fecha probable } \\
\text { del parto. } \\
\text { Cuando se trata de embarazo múltiple, El descanso } \\
\text { postnatal se extenderá por } 30 \text { (treinta) días naturales } \\
\text { adicionales. } \\
\text { Asimismo, la trabajadora tiene derecho a que el período } \\
\text { de descanso vacacional por récord cumplido y o gozado, } \\
\text { se acumule de tal manera que pueda gozar de } \\
\text { vacaciones desde el día siguiente de culminado el } \\
\text { periodo de descanso post-natal. } \\
\text { La madre trabajadora tiene derecho a retornar al mismo } \\
\text { puesto de trabajo, al término del descanso por } \\
\text { maternidad }\end{array}$ \\
\hline Licencia por paternidad & $\begin{array}{l}\text { Ley } 29409 \text { - Ley que concede el derecho de licencia por } \\
\text { paternidad a los trabajadores de la actividad pública y } \\
\text { privada, modificada por la Ley } 30807 \\
\text { DS N } 014-2010-T R \text { - Reglamento } \\
\text { El padre tiene derecho a una licencia por paternidad de } \\
\text { diez (10) días calendario consecutivos, en los casos de } \\
\text { parto natural o cesárea. } \\
\text { Casos especiales: } \\
\text { - Veinte (20) días calendario consecutivos por } \\
\text { nacimientos prematuros y partos múltiples. } \\
\text { - Treinta (30) días calendario consecutivos por } \\
\text { nacimiento con enfermedad congénita terminal o } \\
\text { discapacidad severa. } \\
\text { - Treinta (30) días calendario consecutivos por } \\
\text { complicaciones graves en la salud de la madre. } \\
\text { El plazo de la licencia se puede computar a partir de la } \\
\text { fecha de nacimiento del hijo (a), desde la fecha en que la } \\
\text { madre o el hijo (a) son dados de alta o a partir del tercer }\end{array}$ \\
\hline
\end{tabular}




\begin{tabular}{|c|c|}
\hline & $\begin{array}{l}\text { día anterior a la fecha probable de parto (debe } \\
\text { acreditarse mediante certificado médico) } \\
\text { Si la madre muere durante el parto o mientras goza de } \\
\text { su licencia por maternidad, el padre será beneficiario de } \\
\text { dicha licencia con goce de haber (si le correspondiera a } \\
\text { la madre), de manera que sea una acumulación de } \\
\text { licencias. } \\
\text { Vencida la licencia, el trabajador puede hacer uso de su } \\
\text { descanso vacacional pendiente de goce. }\end{array}$ \\
\hline $\begin{array}{l}\text { Implementación de lactarios en } \\
\text { empresas públicas y privadas }\end{array}$ & $\begin{array}{l}\text { Ley } 29896 \text { - Ley que establece la implementación de } \\
\text { lactarios en las instituciones del sector público y del } \\
\text { sector privado promoviendo la lactancia materna. } \\
\text { La norma obliga a las empresas del sector público o } \\
\text { privado en las que laboren veinte o más mujeres en edad } \\
\text { fértil, a implementar lactarios con el fin de promover la } \\
\text { lactancia materna. } \\
\text { La norma define lactario como un ambiente } \\
\text { especialmente acondicionado y digno para que las } \\
\text { madres trabajadoras extraigan su leche materna durante } \\
\text { el horario de trabajo, asegurando su adecuada } \\
\text { conservación. }\end{array}$ \\
\hline & $\begin{array}{l}\text { Ley } 27240 \text { - Ley de Lactancia Materna, modificada por la } \\
\text { Ley } 28731\end{array}$ \\
\hline Permiso por lactancia materna & $\begin{array}{l}\text { Ley } 27591 \text { - Ley que equipara la duración del permiso por } \\
\text { lactancia de la madre trabajadora del régimen privado } \\
\text { con el público } \\
\text { La norma establece que la madre trabajadora (del } \\
\text { régimen público o privado), al término del período } \\
\text { postnatal, tiene derecho a una hora diaria de permiso } \\
\text { por lactancia materna, hasta que su hijo tenga un año de } \\
\text { edad. } \\
\text { En caso de parto múltiple, el permiso por lactancia } \\
\text { materna se incrementará una hora más al día. Este } \\
\text { permiso podrá ser fraccionado en dos tiempos iguales y } \\
\text { será otorgado dentro de su jornada laboral, en ningún } \\
\text { caso será materia de descuento. }\end{array}$ \\
\hline Licencia por adopción & $\begin{array}{l}\text { Ley } 27409 \text { - Ley que otorga licencia laboral por adopción } \\
\text { La norma señala que el trabajador peticionario de } \\
\text { adopción (en la vía administrativa o judicial), cuando el } \\
\text { niño es menor a } 12 \text { años de edad, tiene derecho a una } \\
\text { licencia con goce de haber correspondiente a treinta días } \\
\text { naturales, contados a partir del día siguiente de expedida } \\
\text { la Resolución Administrativa de Colocación Familiar y } \\
\text { suscrita la respectiva Acta de Entrega del niño o la } \\
\text { Resolución Judicial de Adopción de ser el caso. } \\
\text { Se debe solicitar expresamente al empleador en un plazo } \\
\text { no menor de quince días naturales a la entrega física del } \\
\text { niño. } \\
\text { Si los trabajadores peticionarios de adopción son } \\
\text { cónyuges, la licencia será tomada por la mujer. } \\
\text { Una vez vencida la licencia por adopción, el trabajador } \\
\text { tiene derecho a solicitar el goce del descanso vacacional } \\
\text { que corresponda. } \\
\text { Si el empleador se negara injustificadamente a conceder } \\
\text { la licencia por adopción, se considera como un acto de } \\
\text { hostilidad equiparable al despido. }\end{array}$ \\
\hline
\end{tabular}




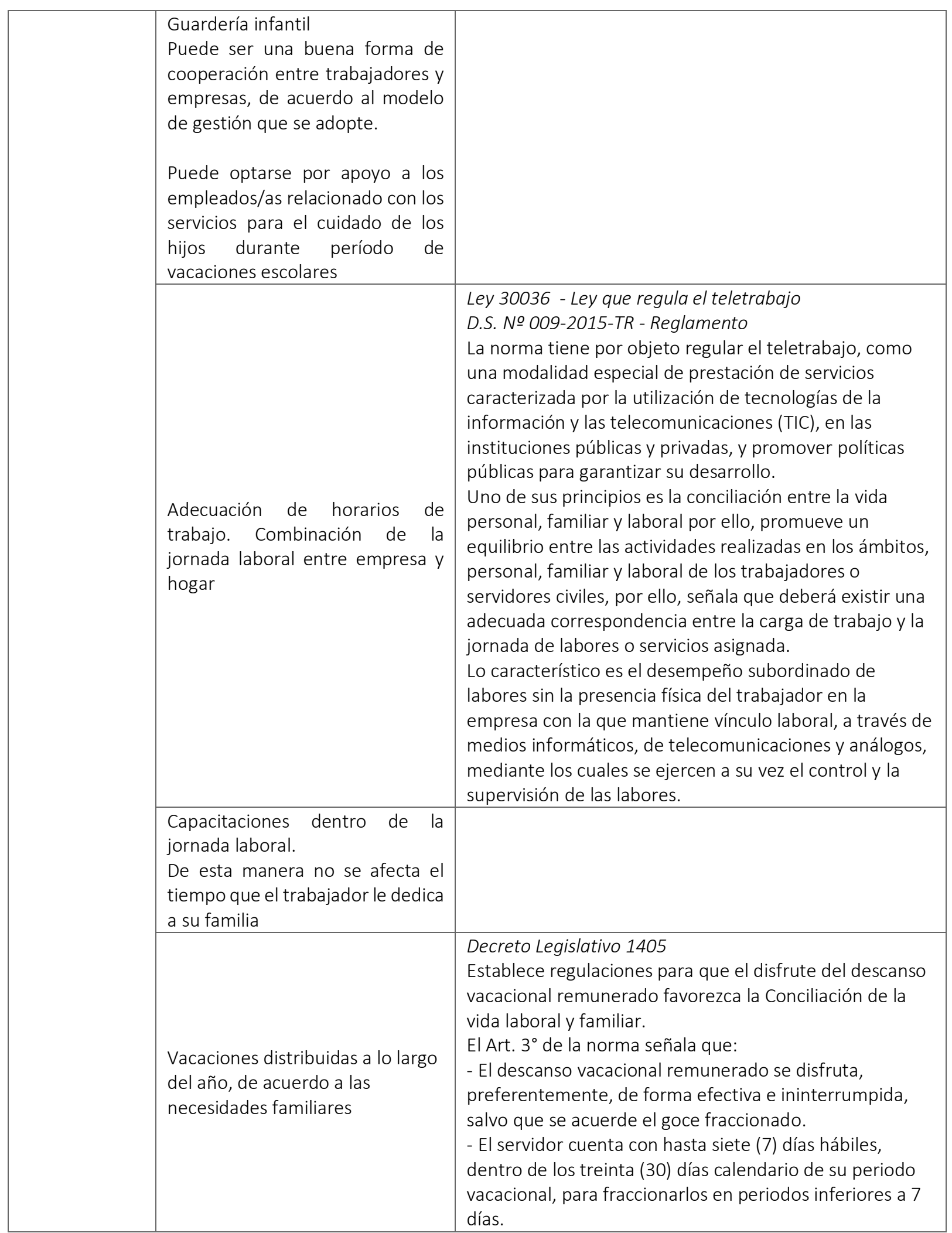




\begin{tabular}{|c|c|c|}
\hline & $\begin{array}{l}\text { Servicios para empleados/as y } \\
\text { familiares en las instalaciones de } \\
\text { la empresa: tintorería, ópticas o } \\
\text { compras en almacenes de ropa } \\
\text { Esto tiene sentido en las grandes } \\
\text { ciudades donde cubrir distancias } \\
\text { para atender encargos suele } \\
\text { reducir gravemente el tiempo en } \\
\text { familia }\end{array}$ & \\
\hline \multirow{4}{*}{$\begin{array}{l}\text { Desarrollo } \\
\text { familiar }\end{array}$} & \multirow[b]{2}{*}{$\begin{array}{l}\text { Licencia para atender familiares } \\
\text { en caso de enfermedad o } \\
\text { necesidad de rehabilitación. }\end{array}$} & $\begin{array}{l}\text { Ley } 30012 \text { - Ley que concede el derecho de licencia a } \\
\text { trabajadores con familiares directos que se encuentran } \\
\text { con enfermedad en estado grave o terminal o sufran } \\
\text { accidente grave } \\
\text { D.S. NNo 008-2017-TR - Reglamento } \\
\text { La norma establece el derecho del trabajador (actividad } \\
\text { pública o privada) a gozar de licencia en los casos de } \\
\text { tener un hijo, padre o madre, cónyuge o conviviente } \\
\text { enfermo diagnosticado en estado grave o terminal, o } \\
\text { que sufra accidente que ponga en serio riesgo su vida, } \\
\text { con el objeto de asistirlo. } \\
\text { El plazo máximo es } 7 \text { días calendario. Los días adicionales } \\
\text { se conceden a cuenta de vacaciones y en caso de exceso } \\
\text { se puede compensar con horas extraordinarias de } \\
\text { labores, previo acuerdo con el empleador. }\end{array}$ \\
\hline & & $\begin{array}{l}\text { Ley } 30119 \text { - Ley que concede el derecho de licencia al } \\
\text { trabajador de la actividad pública y privada para la } \\
\text { asistencia médica y la terapia de rehabilitación de } \\
\text { personas con discapacidad } \\
\text { D.S. No 013-2017-TR - Reglamento } \\
\text { Se establece el derecho de gozar de licencia para la } \\
\text { asistencia médica y la terapia de rehabilitación que } \\
\text { requieran los hijos menores con discapacidad, menores } \\
\text { con discapacidad sujetos a su tutela, mayores de edad } \\
\text { con discapacidad en condición de dependencia o sujetos } \\
\text { a su curatela. } \\
\text { Si ambos padres trabajan para un mismo empleador, } \\
\text { esta licencia es gozada por uno de los padres. } \\
\text { La licencia se otorga hasta por cincuenta y seis horas } \\
\text { alternas o consecutivas anualmente, a cuenta del } \\
\text { período vacacional. También se compensan con horas } \\
\text { extraordinarias de labores, previo acuerdo con el } \\
\text { empleador. Pueden otorgarse horas adicionales. } \\
\text { La norma establece los requisito a cumplir para solicitar } \\
\text { la licencia (documentos que acrediten la necesidad de las } \\
\text { terapias, citas médicas, entre otros). }\end{array}$ \\
\hline & $\begin{array}{l}\text { Beneficio por escolaridad } \\
\text { Se calcula en función del número } \\
\text { de hijos y el nivel de estudios. }\end{array}$ & $\begin{array}{l}\text { En Perú, no existe obligación legal para que las empresas } \\
\text { privadas otorguen bono por escolaridad. } \\
\text { Sin embargo, se entiende que, si la empresa entrega el } \\
\text { bono por escolaridad a sus trabajadores por dos años } \\
\text { consecutivos, este pago se volvería obligatorio. Ello en } \\
\text { virtud de la aplicación de la Sentencia N }{ }^{\circ} 18-44 \text { emitida } \\
\text { por el Tribunal de Trabajo de Lima que señala que una } \\
\text { gratificación extraordinaria anual pierde su carácter } \\
\text { gratuito y unilateral cuando se entrega por dos años } \\
\text { consecutivos. }\end{array}$ \\
\hline & $\begin{array}{l}\text { Becas o bonos para estudios de } \\
\text { hijos }\end{array}$ & \\
\hline
\end{tabular}




\begin{tabular}{|c|c|c|}
\hline & $\begin{array}{l}\text { Préstamos para necesidades o } \\
\text { emergencias familiares }\end{array}$ & \\
\hline & $\begin{array}{l}\text { Programa de verano para los } \\
\text { hijos/as de empleados/as quienes } \\
\text { desempeñan sus labores en } \\
\text { compañía de sus hijos/as. }\end{array}$ & \\
\hline \multirow{4}{*}{$\begin{array}{l}\text { Garantía de } \\
\text { respeto de } \\
\text { DDHH }\end{array}$} & $\begin{array}{l}\text { Medidas de protección a favor de } \\
\text { la mujer gestante }\end{array}$ & $\begin{array}{l}\text { Ley } 28048 \text { - Ley de protección a favor de la mujer } \\
\text { gestante que realiza labores que pongan en riesgo su } \\
\text { salud y/o el desarrollo normal del embrión y el feto } \\
\text { DS N009-2004-TR - Reglamento } \\
\text { La norma establece la facultad de la trabajadora gestante } \\
\text { de solicitar al empleador no realizar labores que pongan } \\
\text { en peligro su salud y/o la del desarrollo normal del } \\
\text { embrión y el feto durante el período de gestación. } \\
\text { Debe mediar certificación médica. } \\
\text { El empleador, una vez recibida la solicitud, deberá tomar } \\
\text { las medidas correspondientes sin que ésas afecten los } \\
\text { derechos laborales de la trabajadora, por ello se } \\
\text { garantiza - al término de la contingencia - el retorno de } \\
\text { la trabajadora a su mismo puesto de trabajo y con la } \\
\text { misma remuneración. }\end{array}$ \\
\hline & $\begin{array}{l}\text { Protección contra despido de } \\
\text { padre, por nacimiento de un hijo. }\end{array}$ & \\
\hline & $\begin{array}{l}\text { Licencia para que el padre } \\
\text { participe en los controles pre } \\
\text { natales }\end{array}$ & \\
\hline & $\begin{array}{l}\text { Igualdad de oportunidades en } \\
\text { ascensos y asignación de tareas } \\
\text { de acuerdo a capacidades. } \\
\text { Igualdad remunerativa en las } \\
\text { mismas condiciones de trabajo y } \\
\text { desarrollo de funciones. }\end{array}$ & $\begin{array}{l}\text { Ley } 30709 \text { - Ley que prohibe la discriminación } \\
\text { remunerativa entre varones y mujeres } \\
\text { La norma tiene como objeto, prohibir la discriminación } \\
\text { remunerativa entre varones y mujeres, mediante la } \\
\text { determinación de categorías, funciones y } \\
\text { remuneraciones que permitan la ejecución del principio } \\
\text { de igual remuneración por igual trabajo. (Art. } 1^{\circ} \text { ) } \\
\text { La norma modifica la Ley } 26772 \text {, modificada por la Ley } \\
27270 \text { y define discriminación como: } \\
\text { "la anulación o alteración de la igualdad de } \\
\text { oportunidades o de trato, en los requerimientos de } \\
\text { personal, a los requisitos para acceder a centros de } \\
\text { educación, formación técnica y profesional, que } \\
\text { impliquen un trato diferenciado basado en motivos de } \\
\text { raza, sexo, religión, opinión, origen social, condición } \\
\text { económica, estado civil, edad o de cualquier índole. Los } \\
\text { empleadores están obligados a informar a sus } \\
\text { trabajadores la política salarial del centro de trabajo. Se } \\
\text { considera práctica discriminatoria brindar un trato } \\
\text { salarial distinto a hombres y mujeres que cumplan los } \\
\text { mismos requisitos de acceso al empleo y desempeñen } \\
\text { las mismas labores" (Art. } 2^{\circ} \text { ) }\end{array}$ \\
\hline $\begin{array}{l}\text { Comunicación } \\
\text { y promoción }\end{array}$ & $\begin{array}{l}\text { Programas de esparcimiento para } \\
\text { la familia, días dedicados a la } \\
\text { familia o visita de los familiares al } \\
\text { centro laboral; con el fin de } \\
\text { establecer un vínculo e } \\
\text { identificación entre la empresa y } \\
\text { la familia del empleador. }\end{array}$ & \\
\hline
\end{tabular}




\begin{tabular}{|l|l|l|}
\hline & $\begin{array}{l}\text { Voluntariado corporativo } \\
\text { sumando a las familias. Con ello } \\
\text { la empresa involucra a la familia } \\
\text { de los trabajadores en las }\end{array}$ & \\
acciones de RSE que tenga & \\
previstas. & \\
\hline $\begin{array}{l}\text { Asesoramiento profesional y } \\
\text { personal para las familias, que } \\
\text { pueden ser autofinanciadas }\end{array}$ & \\
\hline $\begin{array}{l}\text { Seminario, talleres o sesiones de } \\
\text { información sobre la conciliación } \\
\text { laboral o familiar con el fin de } \\
\text { cambiar paradigmas entre los } \\
\text { trabajadores e influir en la cultura } \\
\text { de la organización. }\end{array}$ & \\
\hline $\begin{array}{l}\text { Talleres de fortalecimiento } \\
\text { familiar con el objetivo de } \\
\text { contribuir a la estabilidad familiar } \\
\text { y emocional del trabajador, que } \\
\text { redunda favorablemente en su } \\
\text { desempeño profesional. }\end{array}$ & \\
\hline
\end{tabular}

Elaboración propia 